This item was submitted to Loughborough's Research Repository by the author.

Items in Figshare are protected by copyright, with all rights reserved, unless otherwise indicated.

\title{
Stability and deformation of oil droplets during microfiltration on a slotted pore membrane
}

PLEASE CITE THE PUBLISHED VERSION

http://dx.doi.org/10.1016/j.memsci.2012.01.034

PUBLISHER

(C) Elsevier

VERSION

AM (Accepted Manuscript)

LICENCE

CC BY-NC-ND 4.0

\section{REPOSITORY RECORD}

Ullah, Asmat, R.G. Holdich, M. Naeem, and Victor Starov. 2012. "Stability and Deformation of Oil Droplets During Microfiltration on a Slotted Pore Membrane”. figshare. https://hdl.handle.net/2134/9495. 
This item was submitted to Loughborough's Institutional Repository (https://dspace.lboro.ac.uk/) by the author and is made available under the following Creative Commons Licence conditions.

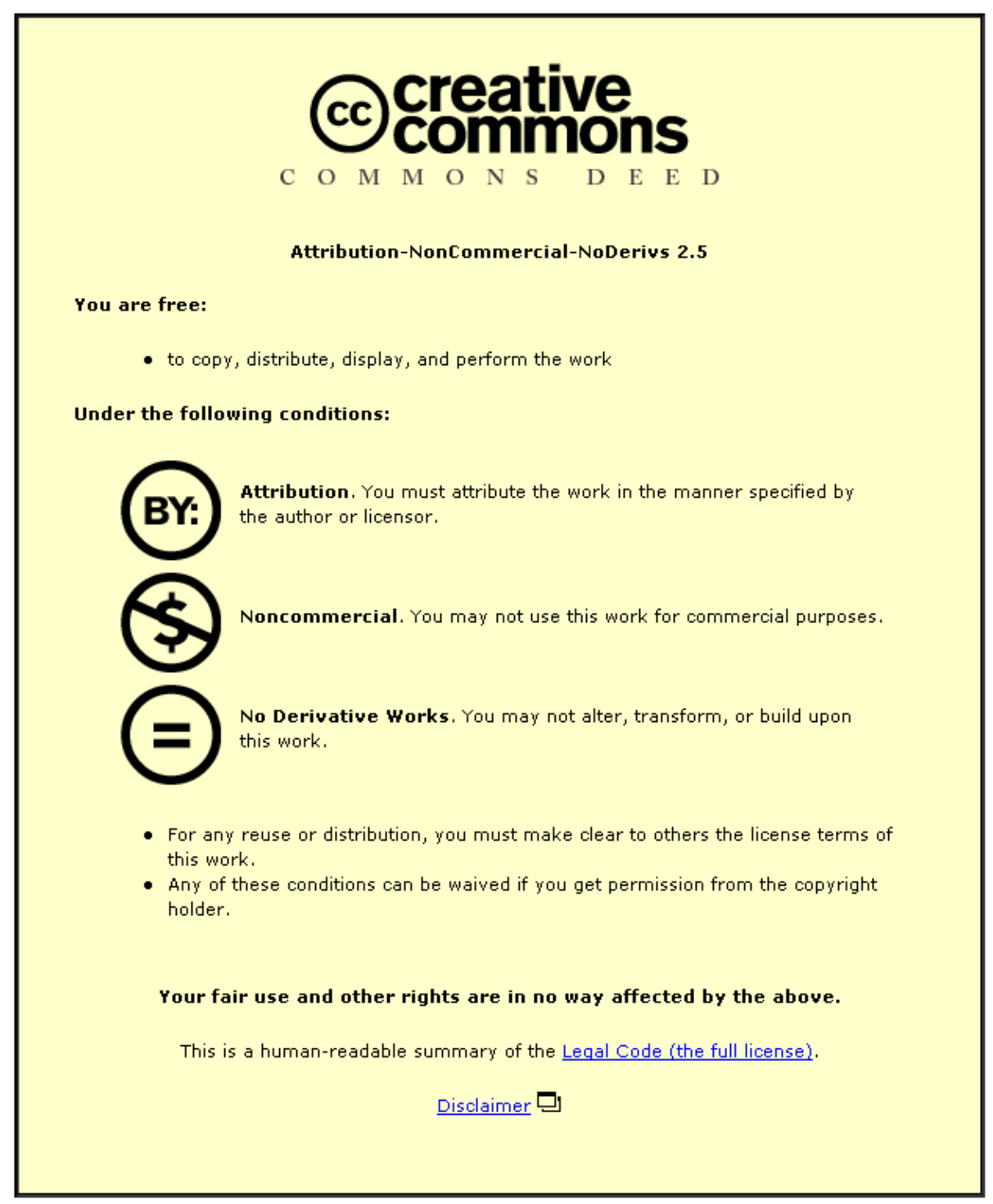

For the full text of this licence, please go to: http://creativecommons.org/licenses/by-nc-nd/2.5/ 


\title{
Stability and deformation of oil droplets during microfiltration on a slotted pore membrane
}

\author{
A. Ullah ${ }^{\text {a,b }}$, R.G. Holdich ${ }^{\mathrm{a}}$, M. Naeem ${ }^{\mathrm{c}}$, V.M. Starov ${ }^{\mathrm{a}}$
}

"To whom correspondence should be addressed: A.Ullah@lboro.ac.uk aDepartment of Chemical Engineering Loughborough University, Leicestershire LE11 3TU, UK

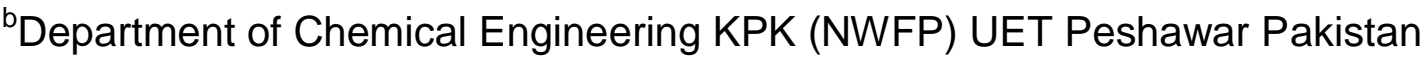
'Department of Chemistry AWKUM Mardan Pakistan.

\section{Abstract}

The effect of interfacial tension between two fluids, on the passage and rejection of oil droplets through slotted pore membranes is reported. A mathematical model was developed in order to predict conditions for $100 \%$ cut-off of oil droplets through the membrane as a function of permeate flux rate. Good agreement of theoretical predictions with experimental data shows that the model can be applied to the filtration of deformable droplets through slotted pore membranes. At high interfacial tension $(40 \mathrm{mN} / \mathrm{m})$ with lower flux $\left(200 \mathrm{I} \mathrm{m}^{-2} \mathrm{hr}^{-1}\right)$ droplets of crude oil $\left(27^{\circ} \mathrm{API}\right)$ were $100 \%$ rejected at droplet diameter $4.3 \mu \mathrm{m}$ using a $4 \mu \mathrm{m}$ slotted pore membrane. At lower interfacial tension $(5 \mathrm{mN} / \mathrm{m})$, with the same flux rate, $100 \%$ rejection occurred at $10 \mu \mathrm{m}$ droplet diameter using the same membrane. It was also found that the droplet rejection efficiency below the $100 \%$ cut-off was roughly linear with drop size, down to zero rejection at zero drop diameter. Hence, the model, coupled with this approximate correlation, can be used to predict dispersed oil drop concentration from a known feed drop size distribution.

Key words: Microfiltration, Interfacial tension, droplet stability, Crude oil 


\section{Introduction}

Dispersed oil droplets in water represent an environmental problem and are associated with a number of chemical industries, especially with offshore oil production. Produced Water is the water coming from the oil reservoir and it contains crude oil droplets of different sizes. It can be disposed of by re-injecting into oil fields, but in many cases it is discharged into the sea. The quantities of Produced Water discharged into the sea ranges from 860 to $2700 \mathrm{~m}^{3}$ day $^{-1}$ [1]. This poses a threat to aquatic life and the amount of oil in Produced Water that can be discharged into the sea is limited to $30 \mathrm{mg} \mathrm{l}^{-1}$ [2]. Hydrocyclones can be used as a secondary separator, after gravity sedimentation, for removal of oil content from Produced Water. However, they are mainly efficient for droplets above $20 \mu \mathrm{m}$ and for light oil drops [3; 4].

Various membrane separation techniques can be used for the removal of oil droplets from water. Ultrafiltration is useful with low oil content, but has permeate flux rates lower than $100 \mathrm{I} \mathrm{m}^{-2} \mathrm{hr}^{-1}$ which is too low to be commercially attractive offshore [5; 6]. For Produced Water microfiltration has been studied by various researchers [7-11]. Higher flux rates (above $100 \mathrm{I} \mathrm{m}^{-2} \mathrm{hr}^{-1}$ ) were achieved. Permeate flux rates in microfiltration depend on droplet size and type of membrane used. Particles/droplets can be retained inside the membrane [12; 13], using filters/membranes with complex and torturous internal structures, and this can cause severe fouling of the membrane used. Recently, developments in membrane pore size and geometry has attracted great interest. Membranes with circular pores are often investigated [14]. Using the same trans-membrane pressure, a membrane with smaller pore size $(2 \mu \mathrm{m})$ has higher efficiency for separating oil droplets up to $10 \mu \mathrm{m}$ compared to a $5 \mu \mathrm{m}$ membrane [14]. Even better separation of oil droplets was achieved with slotted pore-filters under lower trans-membrane pressure [13]. Different mechanisms govern 
the droplet passing through the membrane when circular, or slotted pores are used. When using circular pores, it is the trans-membrane pressure that governs the droplets passing through the membrane into the permeate, while in the case of the slotted pores it is the drag force around the droplets induced by the motion of the fluid that is responsible for the droplets passing through the membrane [2]. Deformation of droplets occurs when the size of drop is bigger than the size of slot or pore. It is possible for a drop to completely block off a circular pore by plugging it. However, it is not possible for a spherical drop to completely plug a slot; there will always be space around the drop for permeate to flow through. Hence, the pressure differential forcing the retained drops through the pores of a filter will be different: in the case of the plugged circular pore filter it is the pressure drop across the filter, whereas in the case of the slot it is the liquid drag that acts to force the drop to deform and pass into the permeate. The deforming force on a slotted pore membrane will be less than that for a circular pore membrane, under otherwise identical operating conditions.

Filtration of deforming droplets is still a challenge for researchers. During filtration the shape of the droplets deforms from spherical and this depends upon the geometry of the pore of the membrane. In this paper the influence of interfacial tension on deformation of the oil droplets through a membrane is investigated. A theoretical model is used to predict the equilibrium position of a droplet on a slot of a membrane by a balance between the static force and drag force.

\section{Theory}

The relevant theory was introduced earlier in [2], where the derivation was not provided, and the final equation given contained an error and requires modification 
for the current case. The detailed derivation is presented here in the appendix. Equations are obtained by the energy balance approach on a droplet using the static deformation force $\left(\mathrm{F}_{\mathrm{c}}\right)$ and the force causing that deformation coming from the liquid that can also be referred to as drag force $\left(F_{d}\right)$ see Figure 1. $F_{c x}$ is the $x$ coordinate of the static droplet deformation force $\mathrm{F}_{\mathrm{c}}$. This model can be applied for the theoretical prediction of $100 \%$ rejection of oil drops in the slot of the membrane under various flux rates. It is assumed when a spherical droplet having radius $\left(R_{s p}\right)$ passes through the slot with a half width $\mathrm{h}$, if the size of droplet is bigger than the slot half width it will deform into an ellipsoid with a bigger radius $\left(R_{\text {ell }}\right)$. The slot converges with an inside angle of $\alpha$.

The excess capillary energy $E_{c a}$ required to squeeze a droplet from a sphere to ellipsoid is the difference in surface area of ellipsoid $\left(S_{\text {ell }}\right)$ and sphere $\left(S_{s p}\right)$ multiplied by interfacial tension $(\gamma)$.

$$
E_{c a}=\gamma\left(S_{e l l}-S_{s p}\right) .
$$

The surface area of a sphere is

$$
S_{s p}=4 \pi R_{s p}^{2}
$$

The surface area of a spheroid is

$$
S_{e l l}=2 \pi R_{s p}{ }^{2}\left(\lambda^{2}+\frac{\arccos \lambda^{3}}{\lambda \sqrt{1-\lambda^{6}}}\right)
$$

where $h$ is the half width of slot of the membrane and $\lambda=\frac{h}{R_{\text {ell }}}$. As shown in the Appendix 
$F_{c x}=+2 \sin \frac{\alpha}{2} \times 2 \pi \gamma R_{s p}{ }^{2}\left(+\frac{3 \lambda^{3}+\frac{\arccos \lambda^{3}}{\sqrt{1-\lambda^{6}}}\left(1-4 \lambda^{6}\right)}{\lambda^{2}\left(1-\lambda^{6}\right)}-2 \lambda\right)$

The drag force exerted on a sphere moving between parallel pates is given as in [15] $F_{d}=k_{w} F_{o}$, where $k_{w}$ is a wall correction factor and $F_{o}$ is the drag force and can be obtained using Stokes drag expression. Here $\eta$ is viscosity of the fluid, $R_{s p}$ is the radius of the droplet and $U$ is the velocity of the fluid.

$F_{d}=k_{w} 6 \pi \eta R_{s p} U$

The droplet will be under steady state conditions when $F_{c x}$ becomes equal to $F_{d}$ and will stay on the surface of the membrane. The droplet will deform and will pass through the membrane when $F_{d}>F_{c x}$ and it will be rejected by the membrane in the case of $F_{c x}>F_{d}$.

\section{Experimental}

\subsection{Materials}

Crude oil was supplied by North Sea operating companies. Vegetable oil was obtained from a local supermarket (EU Rapeseed Co-operative group Ltd, UK). Tween 20 (Fluka, UK), gum Arabic and PVA (Sigma Aldrich, UK) were used as surfactants for vegetable oil droplet stability. Silica $\left(\mathrm{SiO}_{2}\right)$ (Degussa AG, Germany) was used to enhance oil droplet stability by decreasing the deformation of the droplets when subjected to high trans-membrane pressure during filtration, by increasing the interfacial tension between the oil droplet and water. Oil droplets were produced using a food blender (Kenwood Manufacturing Co Ltd Havant Hants, 
England). For the measurement of interfacial tension the Du Nouy ring method with a White Electric Instrument tensiometer (model DB2KS) was used [16]. Viscosities were measured by HAAKA RheoStress model RS600 rheometer with sensor MV2. A Coulter Multisizer II (Coulter Counter, Coulter Electronics Ltd) was used to measure the number of dispersed droplets and size distribution. Filtration tests were done by a dead-end candle microfiltration system with a slotted membrane of $4 \mu \mathrm{m}$ slot width and $400 \mu \mathrm{m}$ slot length (Micropore Technologies Ltd, UK) see Figure 2 for an image of an example slotted membrane and Figure 3 for schematic view diagram of the equipment used. To prevent the coalescence of droplets the water/oil emulsion was gently stirred with a magnetic stirrer (Stuart Scientific, SM1, 13519, UK). The membrane was cleaned with Ultrasil 11 and an ultrasonic bath (Fisher Scientific, FB 15046, Germany) was used to agitate the beaker containing Utrasil 11 water solution to clean the membrane.

\subsection{Interfacial tension measurement}

The Du Nouy ring method was used to measure the interfacial tension. A ring is placed inside the dense liquid (water) and pulled out towards the light liquid (oil) until it detached from the dense phase. The force $(F)$ required to pull the ring from one phase to another is equal to the interfacial tension between the two liquids multiplied by the length of the perimeter of the ring.

$$
F=4 \pi R \gamma \beta
$$

Where $\mathrm{R}$ is the radius of the ring, $\beta$ is the correlation factor and $\gamma$ is the interfacial tension [16].

\subsection{Emulsion Preparation}


For the surfactants, 1 wt $\%$ gum Arabic and 1\% Tween 20 were dissolved in cold water. The water was heated to $100^{\circ} \mathrm{C}$ to dissolve 1 wt $\%$ PVA, Gum Arabic, Tween 20 and PVA were dissolved with a magnetic stirrer operated at its highest speed so that particles of Gum Arabic did not cluster in water. When used, $0.1 \mathrm{wt} \%$ Silica $\left(\mathrm{SiO}_{2}\right)$ was dispersed in vegetable oil using the magnetic stirrer and $1 \mathrm{ml}$ of the dispersion of silica/vegetable oil was added into $500 \mathrm{ml}$ water Gum Arabic solution. Oil droplets with a diameter of 1 to $15 \mu \mathrm{m}$ were produced using a food blender operated using its highest speed for 12 minutes, a typical size distribution is illustrated in Figure 4a, for the vegetable oil, and Figure 4b for the crude oil.

To test droplet stability samples were analysed at 30 min intervals using the Coulter Multisizer II, but only $2 \mu \mathrm{m}$ and above droplets were measured by the Coulter. Droplets below $2 \mu m$ were also created during the preparation of oil/water emulsion but these were too fine to measure. In all the tests nearly $80 \%$ of the oil by a mass balance was recovered by the Coulter. This means that $20 \%$ by mass of the oil was below the range of the device. The dashed line portion in Figures 4 (a) and Figure 4 (b) shows that part of oil droplets which were not measured by the Coulter, but have been inferred from the mass balance. Droplet stability was established on the basis of consistency in size distributions and number of droplets in samples analysed at 30 minute intervals.

\subsection{Filtration}

A $4 \mu \mathrm{m}$ slot width membrane was used for filtration experiments using the dead-end candle microfiltration system as illustrated in Figure 3. The presence of large droplets in the permeate would indicate higher deformation of the droplets through 
the slots of the membrane. Grade efficiency can be calculated using the following equation [17]

grade efficiency $=\left(1-\frac{\text { permeate mass concentration in grade }}{\text { feed mass concentrationin grade }}\right) \times 100$

Permeate with various flux rates was passed through the membrane, and the effect of the flux rate on grade efficiency and $100 \%$ cut-off was studied. Before and after each run the membrane was cleaned with $2 \%$ Ultrasil 11 and hot $\left(50^{\circ} \mathrm{C}\right)$ filtered water. At different trans-membrane pressures various permeate flux rates were obtained and compared with clean water flux rates at the respective trans-membrane pressures. When these flux rates were similar to the flux rates of the clean water, the membrane was considered cleaned and ready for reuse.

\section{Results and Discussions}

Vegetable oil droplets were stabilised with three different surfactants:1 wt\% PVA, Tween 20 and gum Arabic. Drop stability was established on the basis of size distributions and number of droplets in samples. It is clear from Figures 4 (a) that nearly the same size distribution was obtained for the three samples stabilised with the 1 wt\% PVA surfactant. A similar result was obtained with all surfactants used. Additionally, it is shown in Table 1 that a similar number of droplets were present, irrespective of time, for each surfactant. So it can be concluded, that emulsions were stabilised not only on the basis of size distribution (Figure 4), but also by the number of droplets (Table 1).

According to the mathematical model presented in this paper, the system needs more energy for the deformation and squeezing of the droplets through the slots of the membrane when there is a higher interfacial tension. The drag force and the 
static force are taken into account in the model. Drag force convects the droplets through the slots. It is function of droplet size and fluid velocity around the droplet. It increases linearly with the droplet size. Static force always acts in the opposite direction to the drag force, and tries to reject the droplets from the slots. It depends mainly on the interfacial tension between two fluids. Static force increases linearly with interfacial tension and exponentially with the size of the droplets.

The membrane slot width $(4 \mu \mathrm{m})$ was specified by Micropore Technologies UK. To confirm the slot width, non-deformable silica particles in water were filtered at various flux rates. Figure 5 shows that at various flux rates the $100 \%$ silica particle cut-off was close $4 \mu \mathrm{m}$. So, the slot width was assumed to be $4 \mu \mathrm{m}$ for the mathematical model. A linear fit in Figure 5 is obtained by drawing a straight line connecting the $100 \%$ cut-off theoretical value with the origin of the graph. It provides a reasonable correlation of rejection performance below the $100 \%$ cut-off value.

Figure 6 illustrates the comparison of $100 \%$ cut-off (rejections) points of all the droplets obtained from experimental measurements and theoretical predications. The static force was obtained using eq (4), and drag force from eq (5). A satisfactory agreement between theoretical points and the experimental measured points shows that this model can be used to predict the $100 \%$ cut-off values of the oil types tested here.

Filtration results of oil/water emulsions with various surfactants are illustrated in Figures $7($ a) to Figure $7(d)$. Crude oil droplets show higher oil-water interfacial tension as compared with the vegetable oil (Table 2). The data presented in Table 2 clearly demonstrates decreasing oil drop rejection with decreasing interfacial tension. Hence, increasing oil drop concentration in the permeate. It is notable that the crude 
oil has a significantly higher interfacial tension than the vegetable oils, even when solids were added to help stabilise the vegetable oil drops. On increasing the interfacial tension the cut off value reaches a value close to $4 \mu \mathrm{m}$. The latter value was verified for solid silica particles. Also noticeable is that the higher the flux rate the poorer the drop rejection becomes because of a greater force deforming the drops. These effects are quantifiably predictable using the presented mathematical model. The drop size when the static force and the drag force on the drops balance provides the limiting size for the drops at which $100 \%$ rejection can be expected. The model does not predict the percentage rejection below the $100 \%$ cut-off, but experimentally this appears to follow a linear trend from the predicted $100 \%$ cut-off point to the origin. This is true for the oil drops as well as the solid silica particles. The two limits of the linear fit are, therefore, the theoretical $100 \%$ cut-off value, and the origin. Hence, this linear fit is also quantifiably predicted form the model presented. Thus, for a given feed drop size distribution of oil drops in water, it is possible to predict the $100 \%$ cut-off value and the rejection efficiency at drop sizes below the $100 \%$ cut-off. Thus, the total oil drop distribution and mass concentration of oil in water can be predicted.

\section{Conclusions}

Vegetable oil droplets were stabilised with 1 wt\% gum Arabic, PVA and Tween 20, and crude oil drops were found to be stabilised without the need for any additional surfactants. Stability of droplets was established on the basis of size distributions and number of droplets in the emulsion samples analysed at 30 min intervals. These emulsions provided a range of interfacial tensions and were filtered providing a range of filtration efficiencies. Interfacial tension between oil and water is an important factor that can strongly influence deformation of droplets through the slots 
of the membrane. It was found that an increase in interfacial tension decreased deformation of oil droplets. Interfacial tension of oil/water can be increased by dispersed particles at the interface. Higher interfacial tension was observed for crude oil than vegetable oils. This led to better rejection of crude oil droplets than vegetable oil droplets, but tests used both types in order to validate the numerical model predicting $100 \%$ cut-off. Good agreement of experimental measured points with the theoretical points shows that the concept of drag and static force over a droplet can be efficiently applied for filtering deformable droplets using slotted pore membranes. This work can applied for filtration of emulsions created by Produced Water in the oil and gas industry that contain deformable droplets, for the prediction of $100 \%$ cut-off values and below, as well as the final dispersed phase oil drop concentration.

\section{Appendix A}

A 2-dimensional mathematical model is used in the paper taking a spherical oil drop into account. The shape of drop changes from sphere to spheroid when passing through the slot. The static force acts in the opposite direction to the drag force, and is responsible for the rejection of drops through the membrane, the other forces that may be acting (e.g. body force) are assumed to be insignificant.

A prolate spheroid has surface area

$$
S_{\text {ell }}=\left(h^{2}+\frac{h R_{\text {ell }} \beta}{\sin \beta}\right)
$$

where, $\beta=\arccos \frac{h}{R_{\text {ell }}}$, 

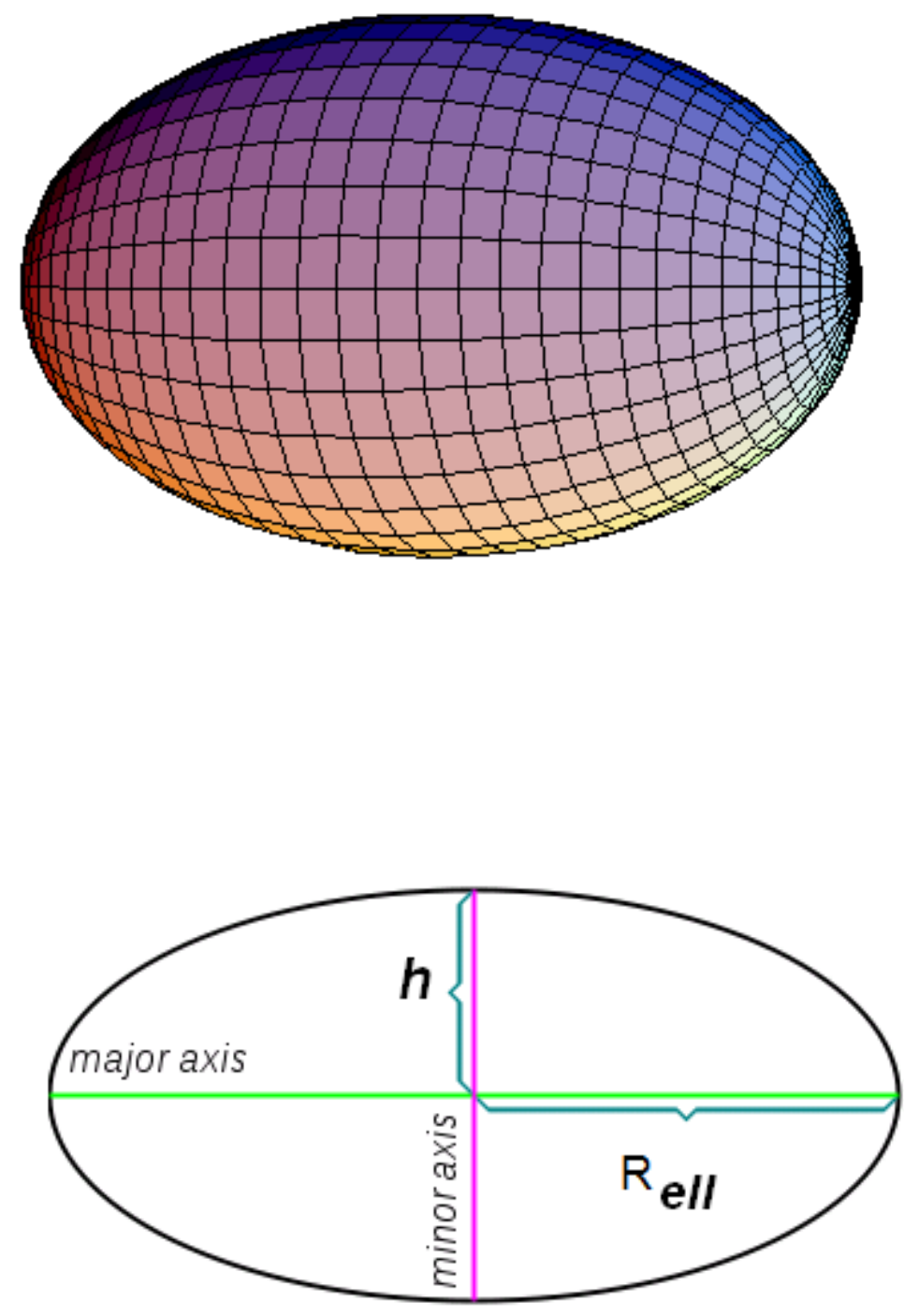

A prolate spheroid can be formed by rotating an ellipse around its major axis.

In the case of a sphere

$V=\frac{4}{3} \pi R_{s p}^{3}$

In the case of a spheroid 
$V=\frac{4}{3} \pi h^{2} R_{e l l}$

For the same drop because of volume conservation we conclude from Eqs (A.2),

(A.3)

$\frac{4}{3} \pi R_{s p}{ }^{3}=\frac{4}{3} \pi h^{2} R_{e l l}$ or $\quad R_{e l l}=\frac{R_{s p}{ }^{3}}{h^{2}}$

According Eq. (A.1)

Hence,

$S_{\text {ell }}=2 \pi\left(h^{2}+\frac{h R_{\text {ell }} \arccos \frac{h}{R_{\text {ell }}}}{\sqrt{1-\left(\frac{h}{R_{\text {ell }}}\right)^{2}}}\right)$

Substitution Eq (A.4) into Eq (A.5) results in

$S_{e l l}=2 \pi\left(h^{2}+\frac{\frac{R_{s p}{ }^{3}}{h} \operatorname{arcco}\left(\frac{h}{R_{s p}{ }^{3}}\right)^{3}}{\sqrt{1-\left(\frac{h}{R_{s p}}\right)^{6}}}\right)=2 \pi R_{s p}{ }^{2}\left(\left(\frac{h}{R_{s p}}\right)^{2}+\frac{\arccos \left(\frac{h}{R_{s p}}\right)^{3}}{\frac{h}{R_{s p}} \sqrt{1-\left(\frac{h}{R_{s p}}\right)^{6}}}\right)$

Hence,

$S_{e l l}=2 \pi R_{s p}{ }^{2}\left(\lambda^{2}+\frac{\arccos \lambda^{3}}{\lambda \sqrt{1-\lambda^{6}}}\right)$ 
Where $\lambda=\frac{h}{R_{s p}}$,

Note, because $0<h<R_{s p}$, hence, $0<\lambda<1$

Hence, the excess capillary energy due to the deformation of the initial sphere into a spheroid is

$$
\begin{aligned}
& E=\gamma\left(S_{e l l}-S_{s p}\right) \\
& =\gamma\left(2 \pi S_{s p}{ }^{2}\left(\lambda^{2}+\frac{\arccos \lambda^{3}}{\lambda \sqrt{1-\lambda^{6}}}\right)-4 \pi R_{s p}{ }^{2}\right)=2 \pi \gamma R_{s p}{ }^{2}\left(\lambda^{2}+\frac{\arccos \lambda^{3}}{\lambda \sqrt{1-\lambda^{6}}}-2\right)
\end{aligned}
$$

Let us introduce $f(\lambda)$

$$
f(\lambda)=\lambda^{2}-2+\frac{\arccos \lambda^{3}}{\lambda \sqrt{1-\lambda^{6}}}
$$

Then,

$$
\frac{E}{2 \pi \gamma R_{s p}{ }^{2}}=f(\lambda), \lambda=\frac{h}{R_{s p}}
$$

Let us plot $f(\lambda)$, at $0<\lambda<1$

At $\lambda \rightarrow 0: f(\lambda) \sim \frac{\frac{\pi}{2}}{\lambda}=\frac{\pi}{2 \lambda} \rightarrow \infty$

At $\lambda \rightarrow 1 ; f(\lambda) \sim 1-2 \lim _{\lambda \rightarrow 1} \frac{\arccos \lambda^{3}}{\lambda \sqrt{1-\lambda^{6}}}=-1+1=0$ 
The plot of $f(\lambda)$ is presented below.

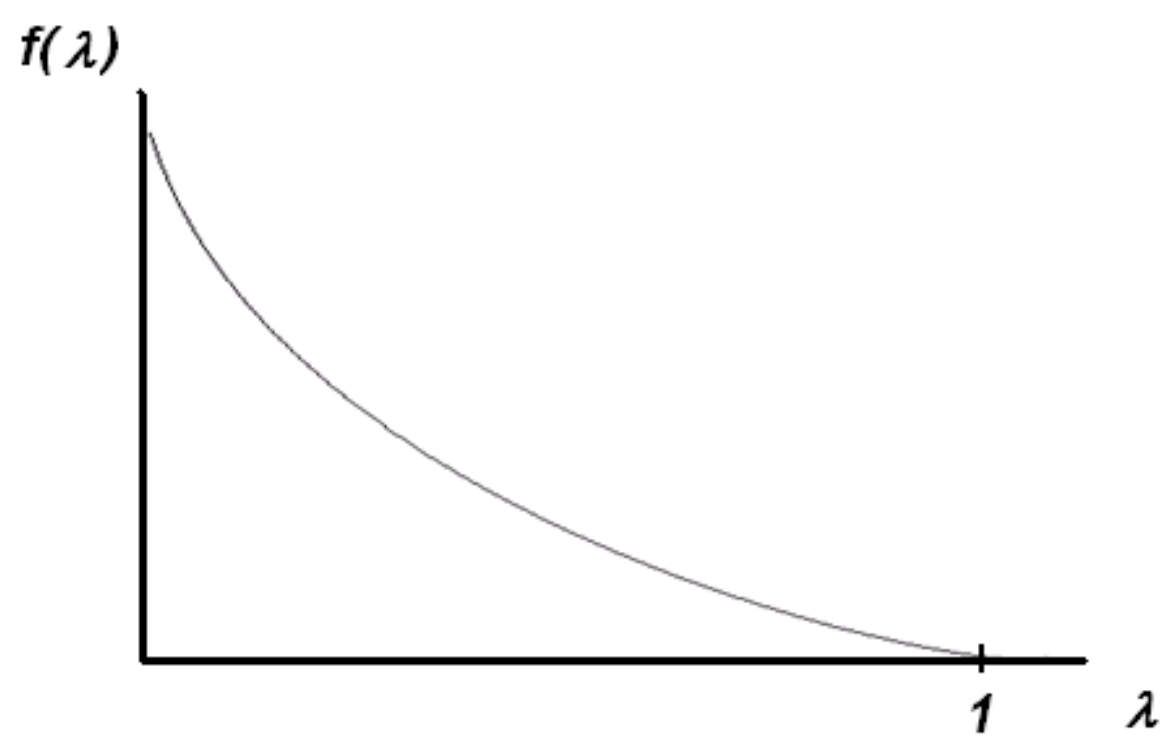

According to [2]:

$F c x=2\left(\frac{\partial E}{\partial I}\right)_{I=R s p-h} \sin \frac{\alpha}{2}$ and taking into account that $d I=-d h$

we conclude that

$F_{c x}=-2 \frac{d E}{d h} \sin \frac{\alpha}{2}$

According to Eq (A.9)

$\frac{d E}{d h}=2 \pi \gamma R_{s p}{ }^{2} f^{\prime}(\lambda)=2 \pi \gamma R_{s p}{ }^{2} f^{\prime}(\lambda)$

From Eq (A.8) we conclude 
$f^{\prime}(\lambda)=2 \lambda-\frac{3 \lambda^{3}+\frac{\arccos \lambda^{3}}{\sqrt{1-\lambda^{6}}}\left(1-4 \lambda^{6}\right)}{\lambda^{2}\left(1-\lambda^{6}\right)}$.

Hence,

$F_{c x}=+2 \sin \frac{\alpha}{2} \times 2 \pi \gamma R_{s p}{ }^{2}\left(+\frac{3 \lambda^{3}+\frac{\arccos \lambda^{3}}{\sqrt{1-\lambda^{6}}}\left(1-4 \lambda^{6}\right)}{\lambda^{2}\left(1-\lambda^{6}\right)}-2 \lambda\right)$

The latter equation is used for comparison with experimental data. 


\section{References}

[1] J.H. Hargreaves, R.S. Silvester, Computational fluid dynamics applied to the analysis of de-oiling hydro-cyclone performance, Trans I Chem E 68 (1990) 365-383.

[2] S.R. Kosvintsev, P.D. Sutrisna, I.W. Cumming, R.G. Holdich, G. Mason, The passage of deforming oil drops through a slotted microfilter, Trans IChemE 85 (2007) $530-536$.

[3] P.G. Grini, M. Hjelsvold, S. Johnsen, Statoil ASA, Trondheim, Choosing Produced Water Treatment Technologies Based on Environmental Impact Reduction, SPE 74 (2002) 1-11.

[4] S. Bednarski, J. Listewnik, Hydrocyclones for simultaneous removal of oil and solid particles from ship's oily waste, Filtration and Separation 25 (1988) 92-97.

[5] S.H. Lin, W.J. Lan, Waste oil/water treatment by membrane processes, J of Hazardous Materials 59 (1998) 189-199.

[6] P. Lipp, C.H. Lee, A.G. Fane, C.J.D. Fell, A fundamental study of ultrafiltration of oil-water emulsions, J Membrane Sci. 36 (1988) 161-177.

[7] A.B. Koltuniewicz, R.W. Field, T.C. Arnot, Cross-flow and mental study and analysis of flux decline, J Membrane Sci. 102 (1995) 193-207.

[8] A.B. Koltuniewicz, R.W. Field, Process factors during removal of oil-water emulsions with cross-flow microfiltration, Desalination 105 (1996) 79-89.

[9] J. Mueller, Y.W. Can, R.H. Davis, Crossflow microfiltration of oily water, J Membrane Sc. 129 (1997) 221-235. 
[10] P. Wang, N. Xu, J. Shi, A pilot study of the treatment of waste rolling emulsion using zirconia microfiltration membrane, J Membrane Sci. 173 (2000) 159-166.

[11] S.S. Madeni, M.K. Yeganeh, Microfiltration of emulsion oil waste water, J of Porous Materials 10 (2003) 131-138.

[12] R.G. Holdich, I.W. Cumming, I.D. Smith, Cross-flow micro-filtration of oil in water dispersions using surface filtration with imposed fluid rotation, J Membrane Sci. 143 (1998) 263-274.

[13] A.J. Bromley, R.G. Holdich, I.W. Cummin, Particulate fouling of surface microfilters with slotted and circular pore geometry, J Membrane Sci. 196 (2002) 2737.

[14] I.W. Cumming, R.G. Holdich, I.D. Smith, The rejection of oil by microfiltration of a stabilised kerosene/water emulsion, J Membrane Sci. 169 (2000) 147-155.

[15] H.J. Keh, Y. Chen Po, slow motion of a droplet between two parallel walls, Chem Eng Sci 56 (2001) 6863-6871.

[16] D.J. McClements Food Emulsions: Principles, Practice and Techniques. CRC Press (1999) 378 pages.

[17] I. W. Cumming R. G. Holdich, I. D. Smith, The rejection of oil using an asymmetric metal microfilter to separate an oil in water dispersion, Wat. Res. 33 (1999) 3587-3594. 


\section{List of Tables}

Table 1 Number of vegetable oil droplets obtained with various surfactants when samples were analysed at the interval of $30 \mathrm{~min}$ at $200 \mathrm{I} \mathrm{m}^{-2} \mathrm{hr}^{-1}$.

Table 2 Interfacial tension, mass of oil in the feed and permeate and $100 \%$ rejection of oil droplets with various surfactants at $200 \mathrm{I} \mathrm{m}^{-2} \mathrm{hr}^{-1}$. 


\section{List of Figures}

Figure 1 Schematic view of deforming droplet at equilibrium position.

Figure 2 Image of the surface of a slotted pore membrane

Figure 3 Schematic view of dead-end candle microfiltration system

Figure 4 (a) Typical size distribution (Cumulative mass undersized "m" VS droplet diameter "d") of the vegetable oil droplets produced stabilised with 1 wt\% PVA.

Figure 4 (b) Typical size distribution (Cumulative mass undersized "m" VS droplet diameter "d") of the crude oil droplets.

Figure 5 Grade efficiency of Silica particles at various flux rates $\left(200,400,600 \mathrm{I} \mathrm{m}^{-2}\right.$ $\left.\mathrm{hr}^{-1}\right)$.

Figure 6 Experimental measurements and theoretical points of $100 \%$ cut-off during filtering vegetable oil droplets with various surfactants (Silica + gum Arabic, Gum Arabic, PVA, Tween20, Crude oil $\left(31^{\circ} \mathrm{API}\right)$ and crude oil $\left(27^{\circ} \mathrm{API}\right)$ with different flux rates $\left(200,400\right.$ and $\left.600 \mathrm{I} \mathrm{m}^{-2} \mathrm{hr}^{-1}\right)$.

Figure 7 (a) Grade efficiency of vegetable oil droplets using gum Arabic and silica combine for droplets stability at various flux rates $\left(200,400,600 \mathrm{I} \mathrm{m}^{-2} \mathrm{hr}^{-1}\right)$.

Figure 7 (b) Grade efficiency of vegetable oil droplets using gum Arabic for droplets stability at various flux rates $\left(200,400,600 \mathrm{I} \mathrm{m}^{-2} \mathrm{hr}^{-1}\right)$.

Figure 7 (c) Grade efficiency of vegetable oil droplets using PVA for droplets stability at various flux rates $\left(200,400,600 \mathrm{I} \mathrm{m}^{-2} \mathrm{hr}^{-1}\right)$. 
Figure 7 (d) Grade efficiency of vegetable oil droplets using Tween 20 for droplets stability at various flux rates $\left(200,400,600 \mathrm{I} \mathrm{m}^{-2} \mathrm{hr}^{-1}\right)$.

Figure 7 (e) Grade efficiency of crude oil $\left(31^{\circ} \mathrm{API}\right)$ droplets at various flux rates $(200$, $\left.400,600 \mathrm{I} \mathrm{m}^{-2} \mathrm{hr}^{-1}\right)$.

Figure 7 (f) Grade efficiency of crude oil droplets (27 $\mathrm{API})$ at various flux rates (200, $\left.400,600 \mathrm{I} \mathrm{m}^{-2} \mathrm{hr}^{-1}\right)$. 
Table 1 Number of vegetable oil droplets obtained with various surfactants when samples were analysed at the interval of $30 \mathrm{~min}$ at $200 \mathrm{I} \mathrm{m}^{-2} \mathrm{hr}^{-1}$

\begin{tabular}{|c|c|c|}
\hline Surfactant & Time $(\mathrm{min})$ & No of droplets per 1 ml sample \\
\hline \multirow{2}{*}{ 1 wt\% Gum Arabic } & 1 & 34280 \\
& 30 & 33193 \\
& 60 & 34151 \\
\hline 1 wt\% PVA & 30 & 43786 \\
& 60 & 44709 \\
& 1 & 42710 \\
\hline wt\% Tween20 & 30 & 54650 \\
& 60 & 53897 \\
& & 51511 \\
\hline
\end{tabular}


Table 2 Interfacial tension, mass of oil in the feed and permeate and $100 \%$ rejection of oil droplets with various surfactants at $200 \mathrm{I} \mathrm{m}^{-2} \mathrm{hr}^{-1}$.

\begin{tabular}{|c|c|c|c|c|}
\hline Substance & $\begin{array}{c}\text { Interfacial Tension } \\
(\mathbf{m N} / \mathbf{m})\end{array}$ & $\begin{array}{c}\text { Mass in Feed } \\
(\mathbf{p p m})\end{array}$ & $\begin{array}{c}\text { Mass in Permeate } \\
(\mathbf{p p m})\end{array}$ & $\begin{array}{c}\mathbf{1 0 0 \%} \text { Cut-off } \\
(\boldsymbol{\mu} \mathbf{m})\end{array}$ \\
\hline Crude oil $\left(27^{\circ} \mathrm{API}\right)$ & 40.0 & 400 & 20 & 4.3 \\
\hline Crude oil $\left(31^{\circ} \mathrm{API}\right)$ & 35.0 & 400 & 30 & 7 \\
\hline $\begin{array}{c}\text { 0.1 wt\% Silica }+1 \\
\text { wt\% Gum Arabic }\end{array}$ & 17.0 & 400 & 50 & 8 \\
\hline $\begin{array}{c}1 \mathrm{wt} \% \text { Gum Arabic } \\
1 \text { wt\% PVA }\end{array}$ & 13.0 & 400 & 70 & 10 \\
\hline 1 wt\% Tween20 & 10.0 & 400 & 100 & 7 \\
\hline
\end{tabular}




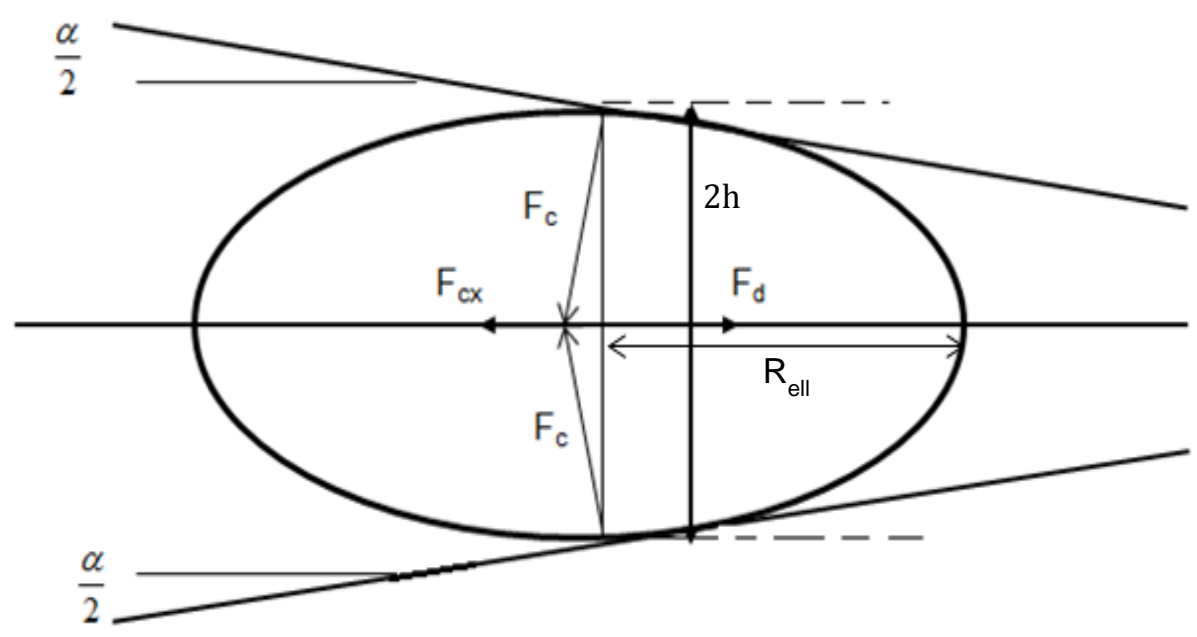

Figure 1 Schematic view of deforming droplet at equilibrium position 


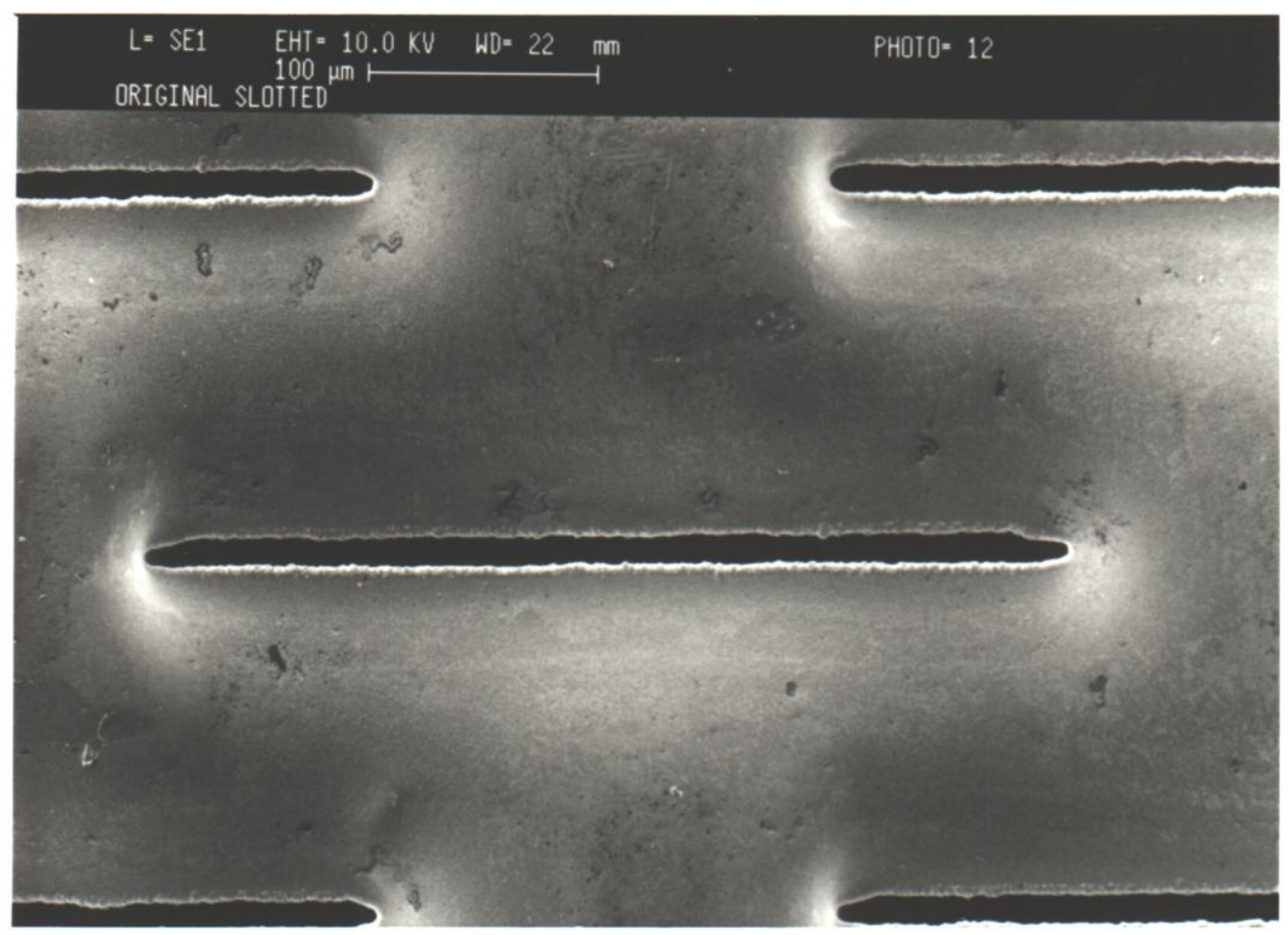

Figure 2 Image of the surface of a slotted pore membrane 


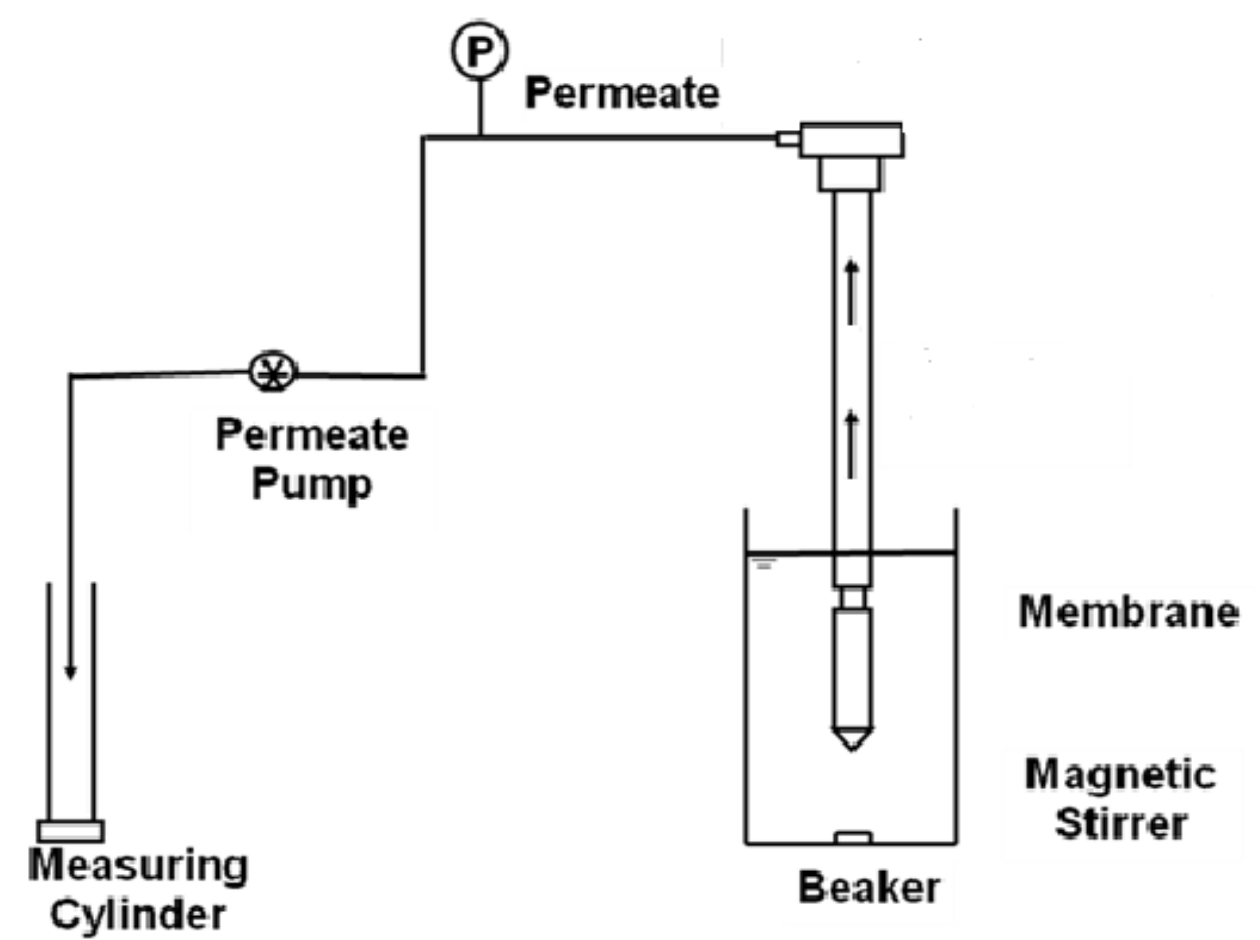

Figure 3 Schematic view of dead-end candle microfiltration system 


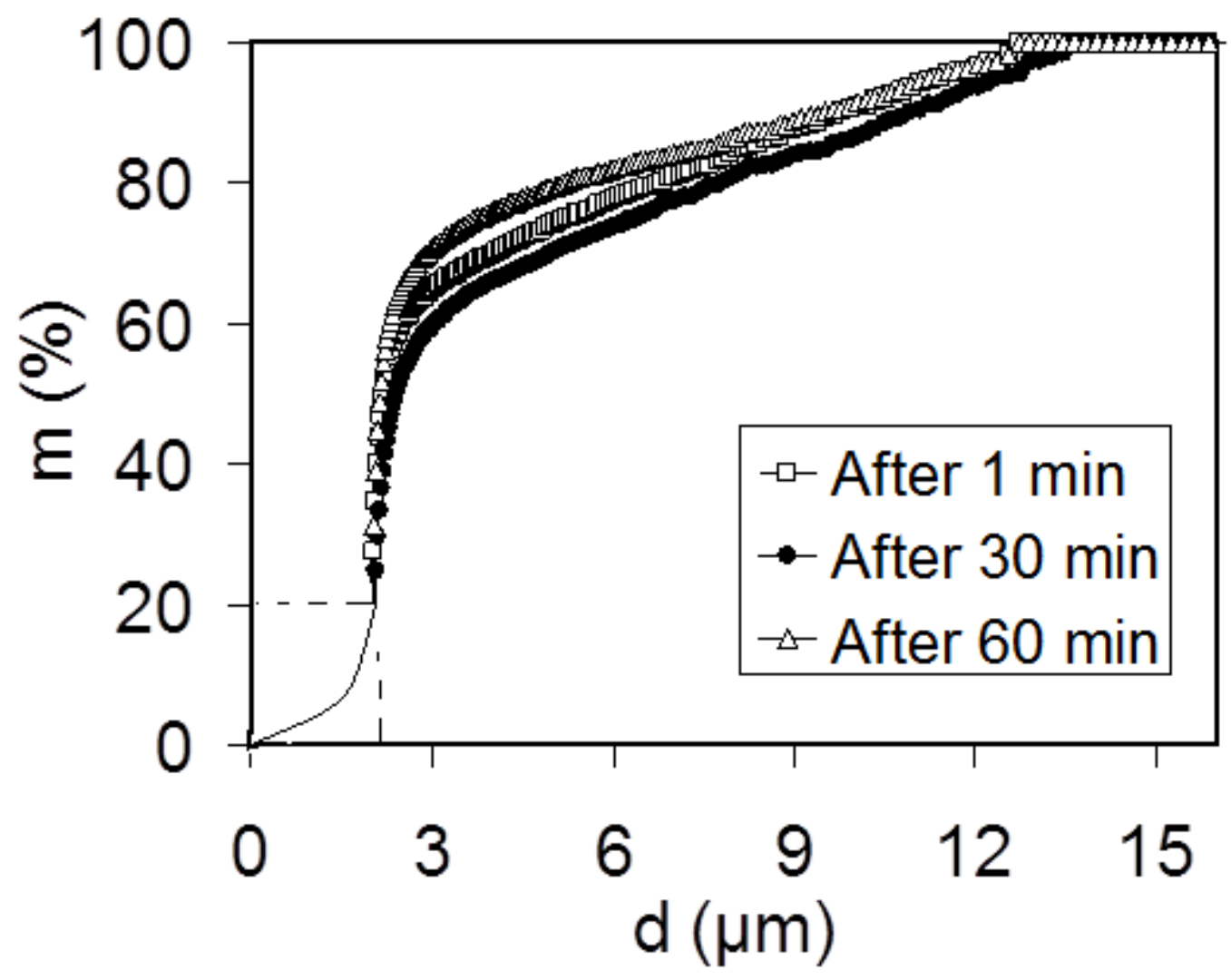

Figure 4 (a) Typical size distribution (Cumulative mass undersized "m" VS droplet diameter "d") of the vegetable oil droplets produced stabilised with $1 \mathrm{wt} \%$ PVA. 


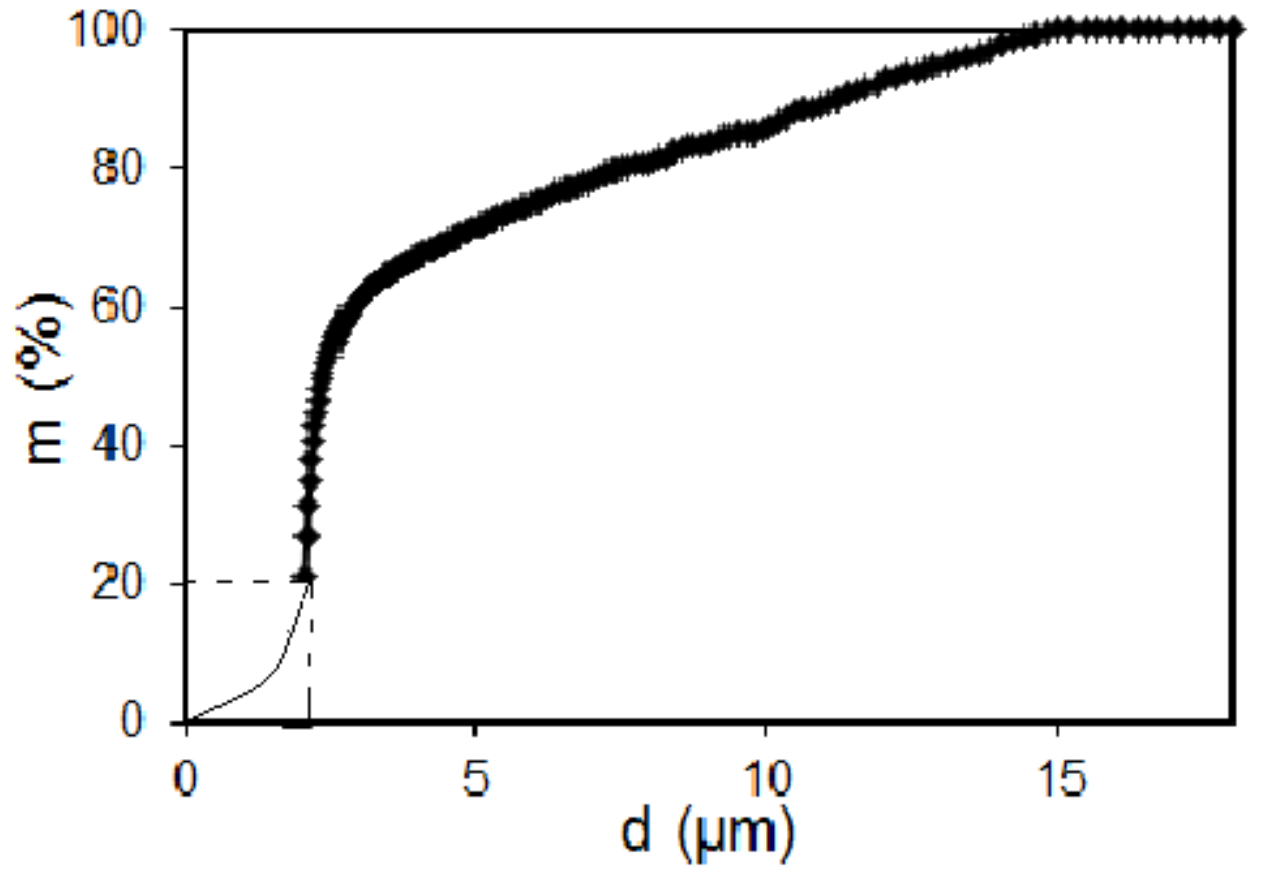

Figure 4 (b) Typical size distribution (Cumulative mass undersized "m" VS droplet diameter "d") of the crude oil droplets $\left(31^{\circ} \mathrm{API}\right)$. 


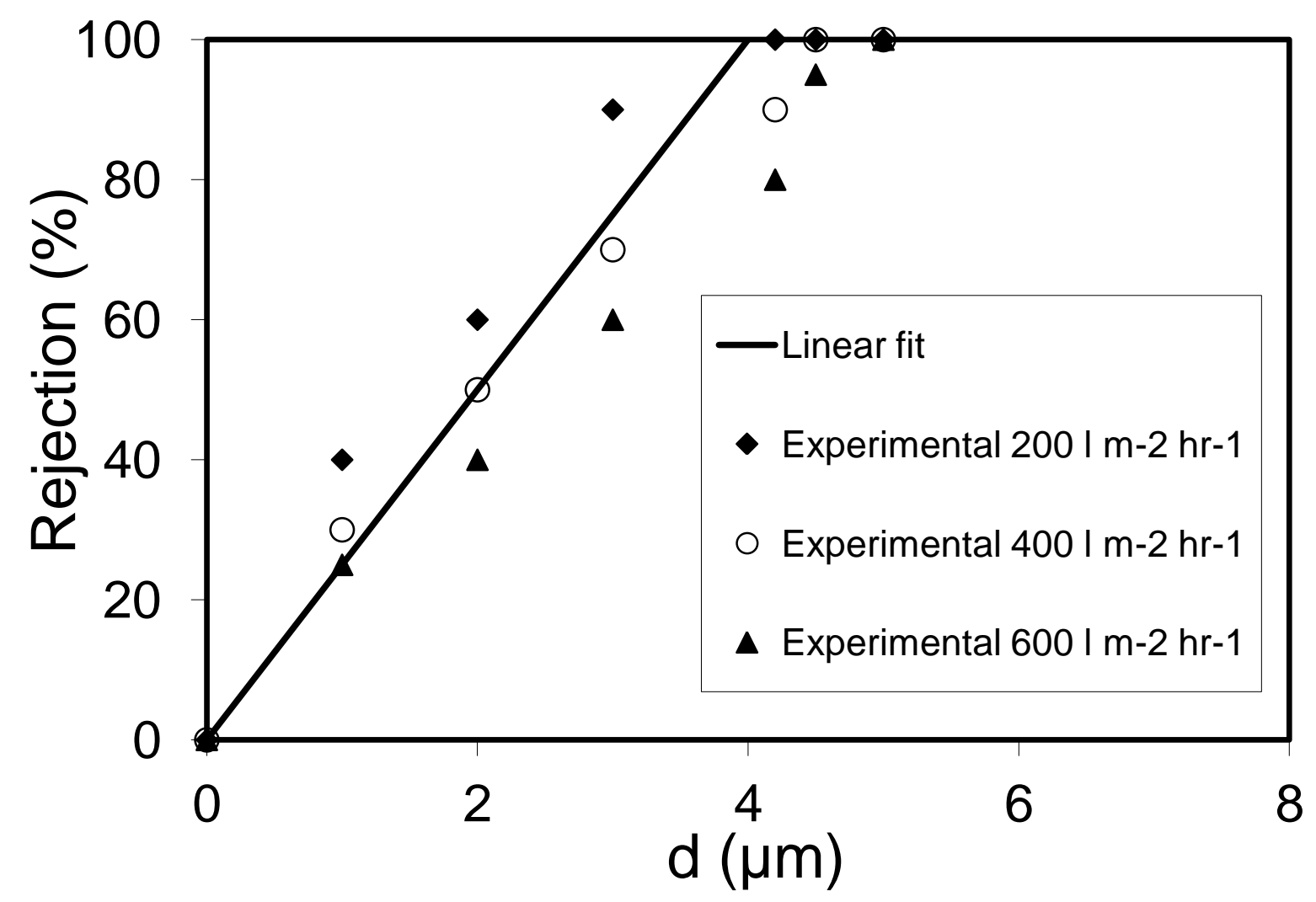

Figure 5 Grade efficiency of Silica particles at various flux rates $\left(200,400,600 \mathrm{I} \mathrm{m}^{-2}\right.$ $\left.h r^{-1}\right)$. 


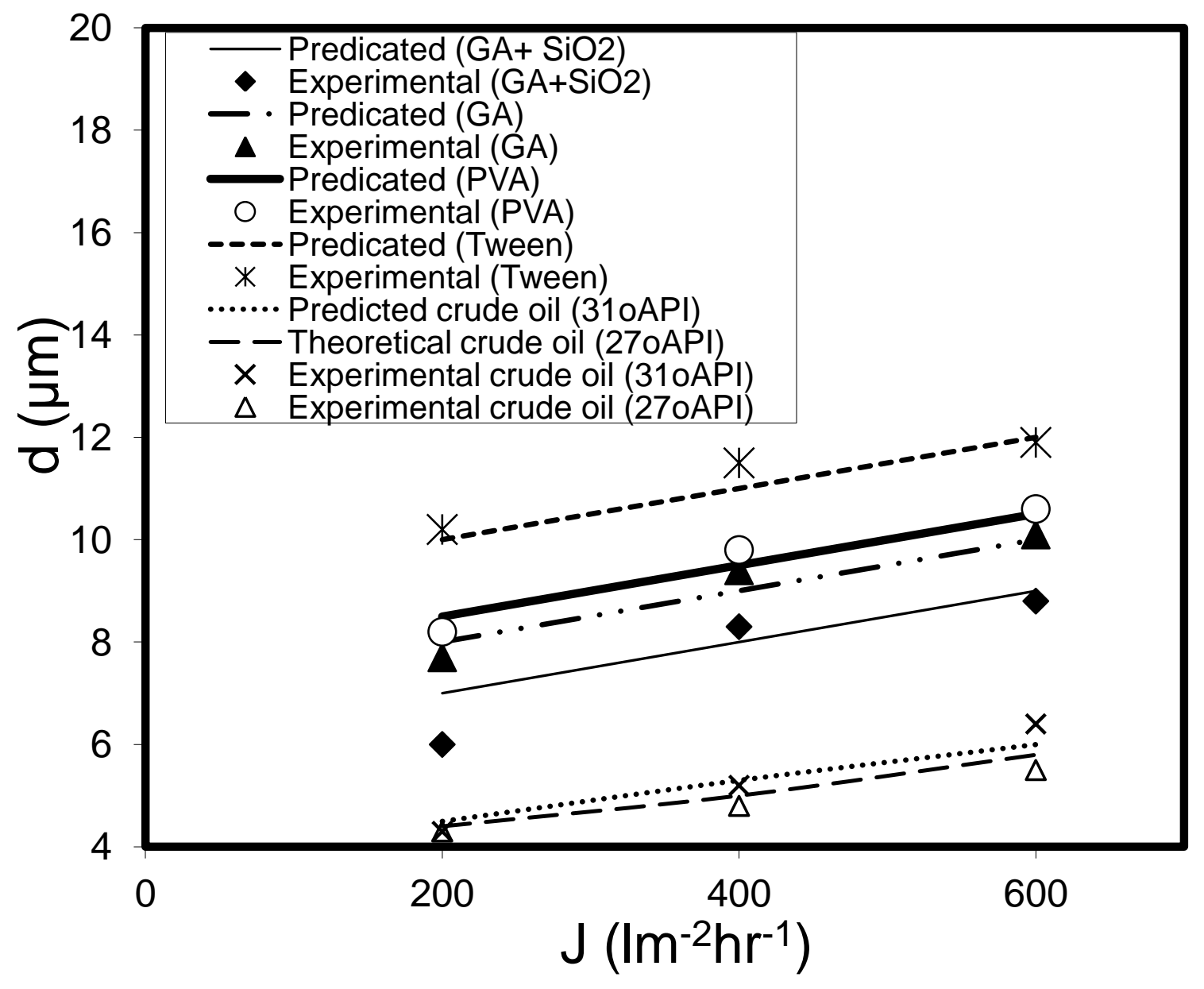

Figure 6 Experimental measurements and theoretical points of $100 \%$ cut-off during filtering vegetable oil droplets with various surfactants (Silica + gum Arabic, Gum Arabic, PVA, Tween20, Crude oil $\left(31^{\circ} \mathrm{API}\right)$ and crude oil $\left(27^{\circ} \mathrm{API}\right)$ with different flux rates $\left(200,400\right.$ and $\left.600 \mathrm{I} \mathrm{m}^{-2} \mathrm{hr}^{-1}\right)$. 


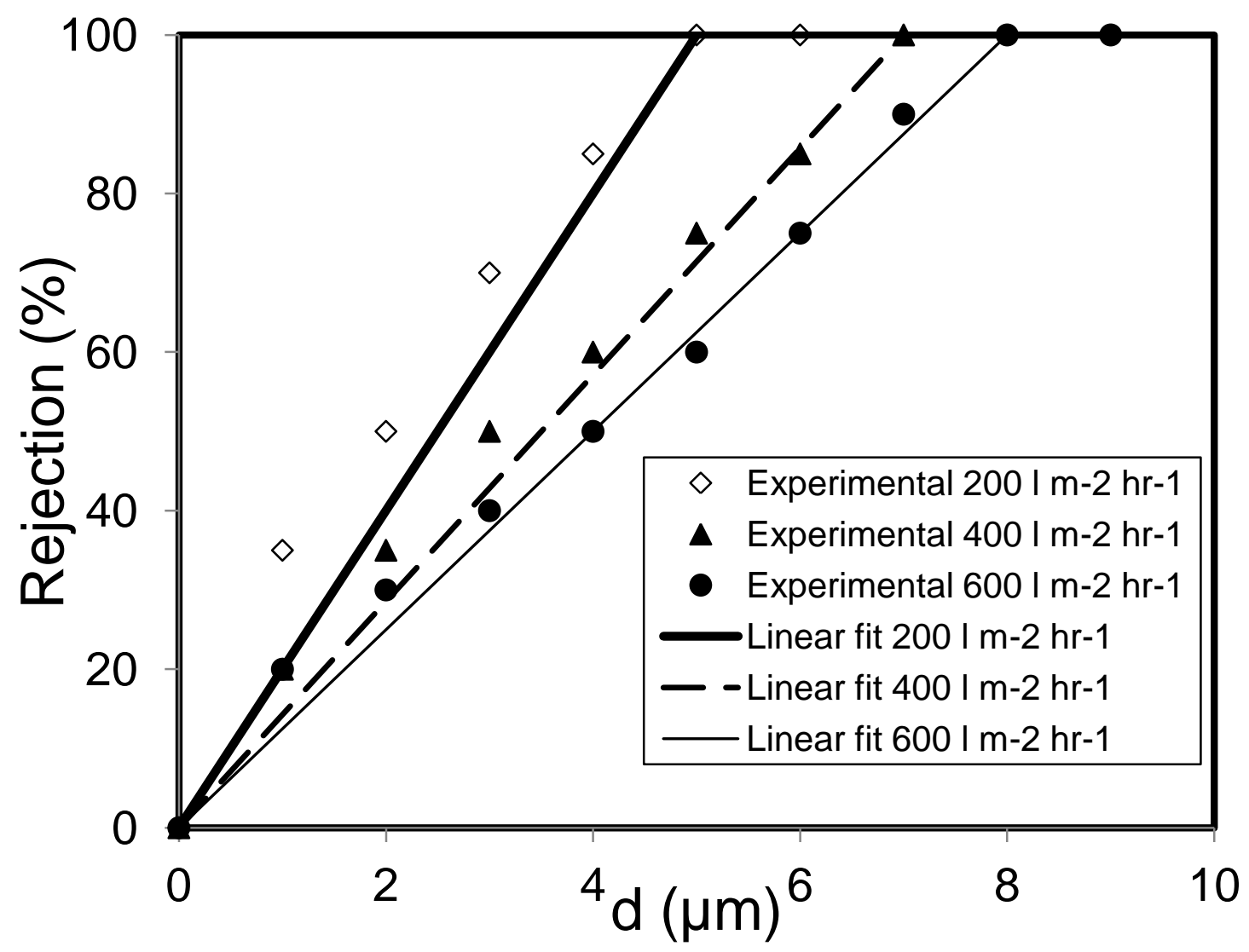

Figure 7 (a) Grade efficiency of vegetable oil droplets using gum Arabic and silica combine for droplets stability at various flux rates $\left(200,400,600 \mathrm{I} \mathrm{m}^{-2} \mathrm{hr}^{-1}\right)$. 


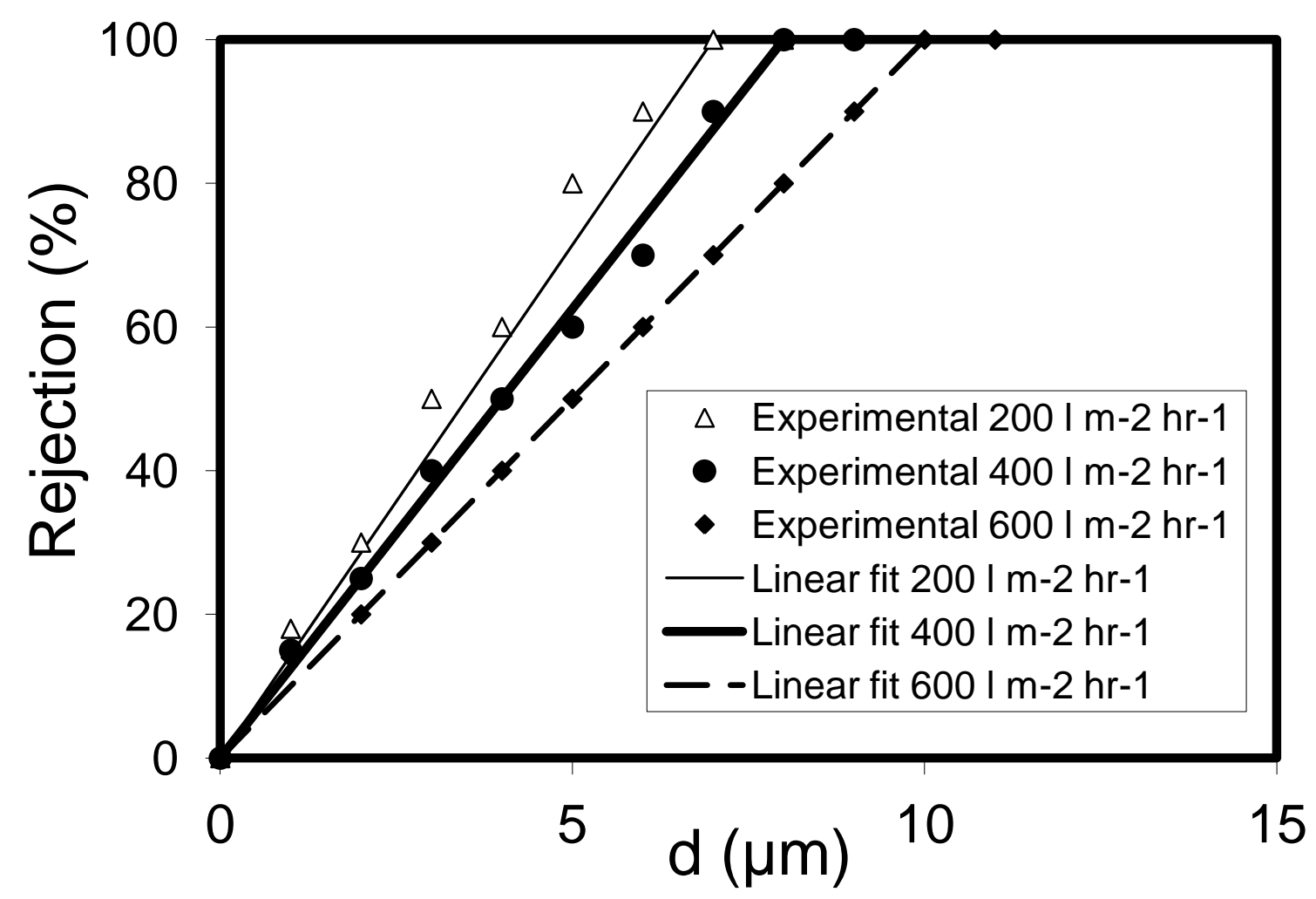

Figure 7 (b) Grade efficiency of vegetable oil droplets using gum Arabic for droplets stability at various flux rates $\left(200,400,600 \mathrm{I} \mathrm{m}^{-2} \mathrm{hr}^{-1}\right)$. 


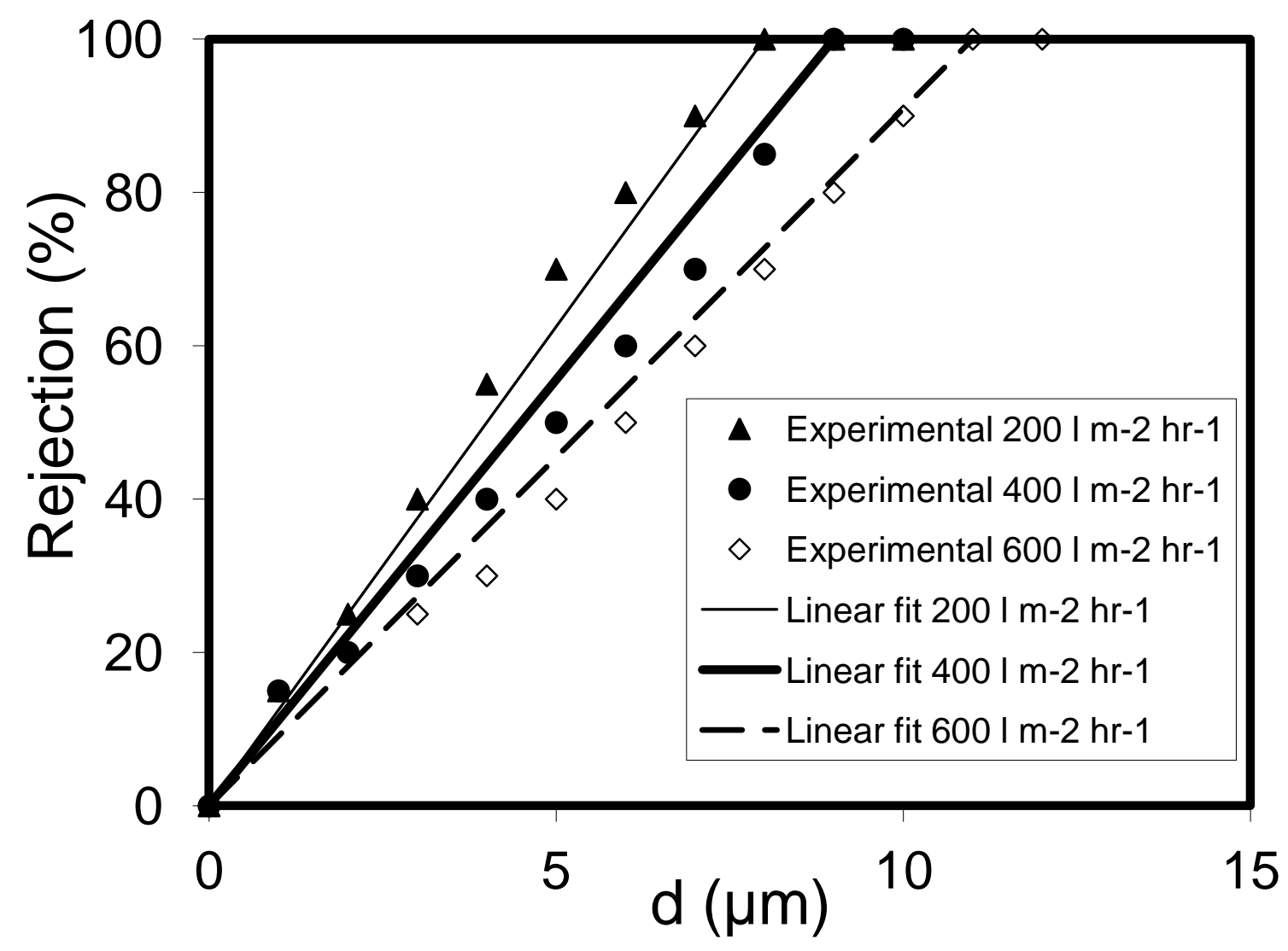

Figure 7 (c) Grade efficiency of vegetable oil droplets using PVA for droplets stability at various flux rates $\left(200,400,600 \mathrm{I} \mathrm{m}^{-2} \mathrm{hr}^{-1}\right)$. 


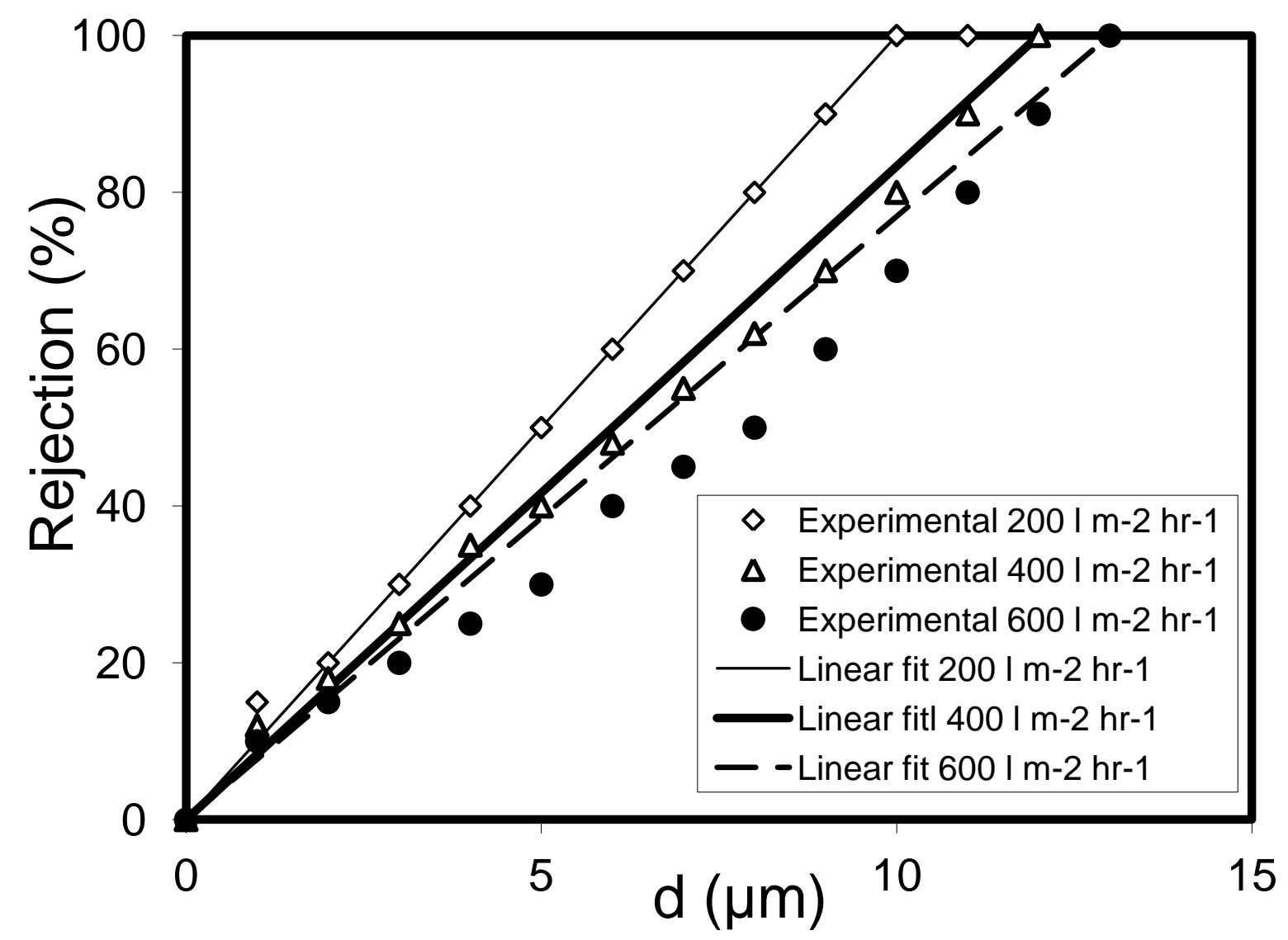

Figure 7 (d) Grade efficiency of vegetable oil droplets using Tween 20 for droplets stability at various flux rates $\left(200,400,600 \mathrm{I} \mathrm{m}^{-2} \mathrm{hr}^{-1}\right)$. 


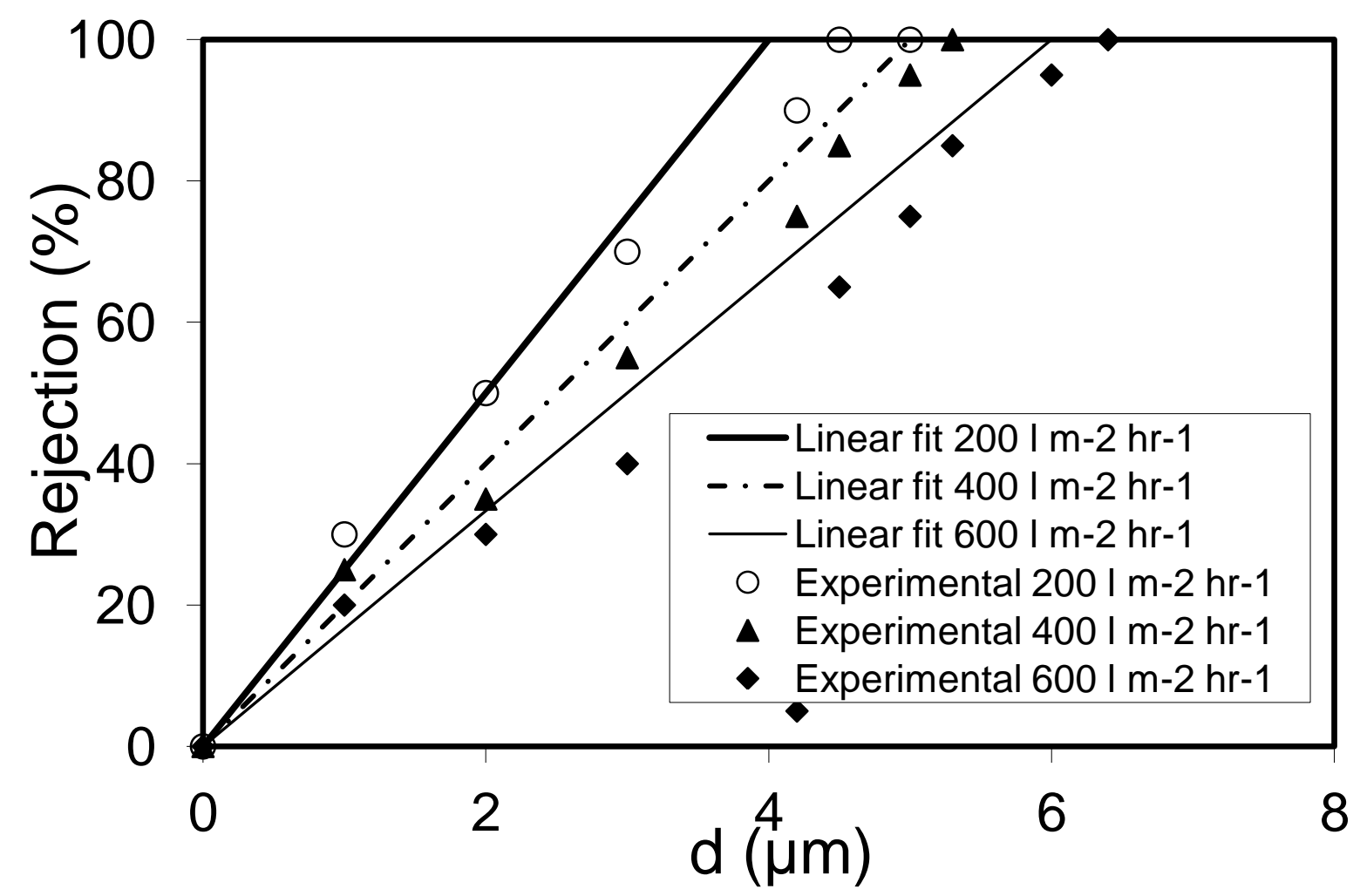

Figure 7 (e) Grade efficiency of crude oil $\left(31^{\circ} \mathrm{API}\right)$ droplets at various flux rates (200, $\left.400,600 \mathrm{I} \mathrm{m}^{-2} \mathrm{hr}^{-1}\right)$. 


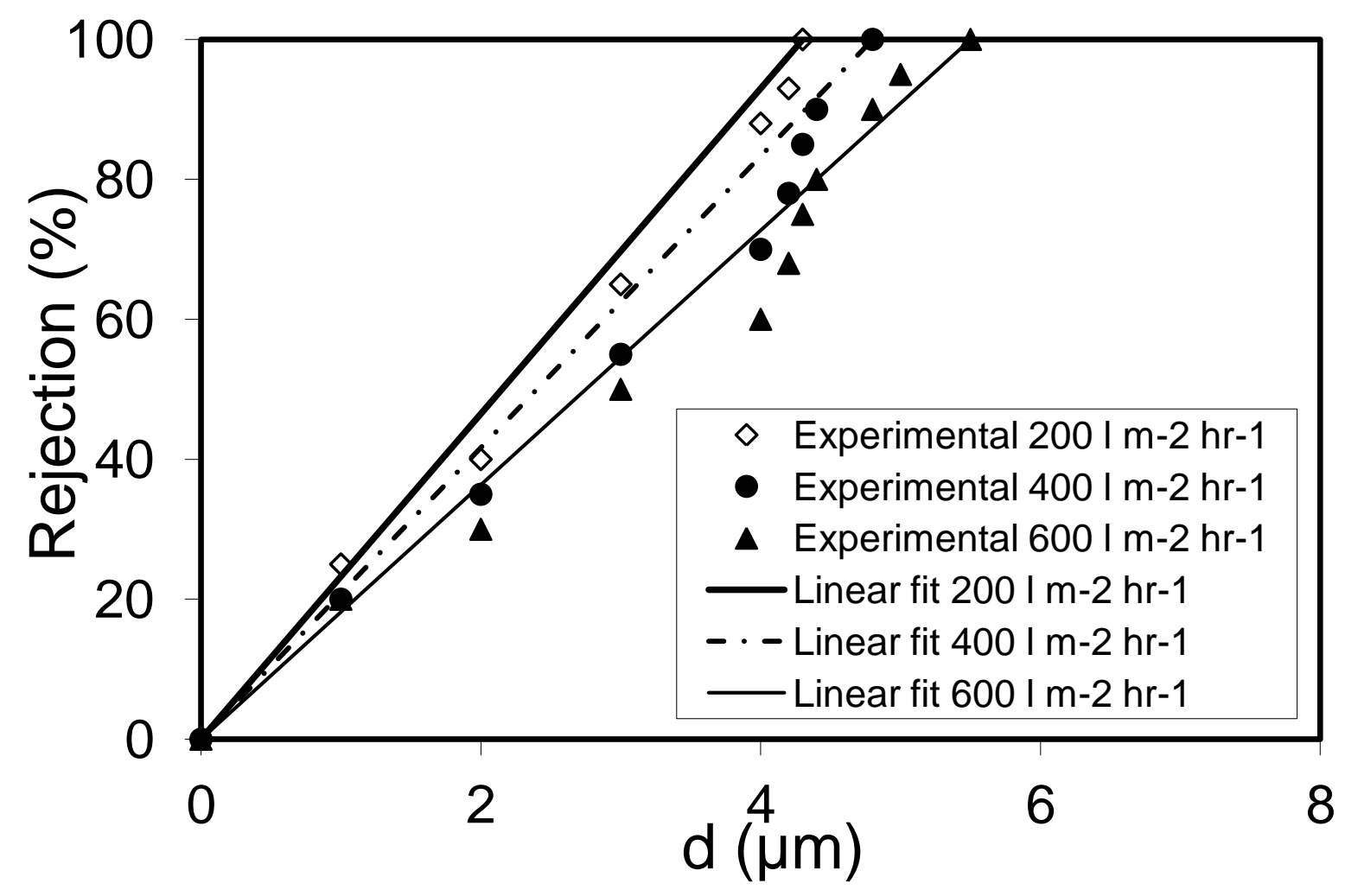

Figure 7 (f) Grade efficiency of crude oil droplets (27 $\mathrm{API})$ at various flux rates (200, $\left.400,600 \mathrm{I} \mathrm{m}^{-2} \mathrm{hr}^{-1}\right)$. 